\title{
Anti-infective treatment in HIV-infected patients during perioperative period
}

\author{
Baochi Liư ${ }^{1 *}$, Lei Zhang ${ }^{1,3}$, Ruizhang Guo², Jinsong Su', Lei Li and Yanhui Si
}

\begin{abstract}
Objective: To investigate anti-infective treatments in HIV-infected surgical patients during the perioperative period. Methods: A retrospective study of sepsis and surgical site infections (SSIs) was conducted in 266 HIV-infected patients. The patients were divided into 3 groups based on CD4+ T cells counts in the preoperative period: group A (0-199 cell/ul), group B (200-349 cell/ul) and group C ([greater than or equal to] 350 cell/ul). When the CD4 count was below 350 cells/uL, anti-retrovirus therapy was started. For patients whose preoperative CD4 counts were [less than or equal to] 200 cells/uL, preoperative antibiotic medication was started.
\end{abstract}

Results: Patients in group A were more likely to get sepsis than patients in the other two groups (p0.01). Among 82 patients with clean wounds, only one patient got SSIs. All patients with dirty wounds had acquired SSIs after surgery. There were only 6 patients dead at 30 days after surgery, a death rate of $2.3 \%$. Sepsis appeared in 110 patients (41\%).

Conclusions: Complete evaluation of surgical risk and suitable perioperative anti-infective treatment may lead to better outcome for HIV-infected surgical patients.

Keywords: HIV/AIDS, Surgical site infection, Sepsis, Anti-infective treatment

\section{Introduction}

The patient who undergoes surgical treatment may experience postoperative infection. According to wound class and immune status, the postoperative infection rates are different. Based on the National Nosocomial Infections Surveillance (NNIS) system, surgical site infections (SSIs) are the third most frequently reported nosocomial infection, and the most common on surgical wards [1]. The Centers for Disease Control and Prevention (CDC) estimates that $22 \%$ of all health-careassociated infections are SSIs, with an increasing percentage over the last decade $[1,2]$. SSIs increase morbidity as well as mortality, double the length of hospital stay [3-6] and increase the cost of surgery two- to fivefold [7].

The progressive failure of the immune system caused by HIV can increase the possibility of developing postoperative infection. In recent years, the number of HIV-

\footnotetext{
* Correspondence: liubaochi2002@yahoo.com.cn

'Department of Surgery, Shanghai Public Health Clinical Center Affiliated to Fudan University, 2901 Caolang Road, Shanghai, Jinshan District 201508, China

Full list of author information is available at the end of the article
}

infected patients is progressively increasing. The introduction of antiretroviral therapy (ART) has significantly improved the life expectancy of patients infected with HIV and those diagnosed with AIDS [8-13]. The demand for surgical treatment in HIV-infected patients is increasing and so is the frequency of resultant surgical disease $[14,15]$.

There are few reported data on the efficacy of antiinfective treatment in HIV-infected patients during the perioperative period. Since our institution is a designated tertiary care university hospital for treatment of HIVinfected patients we had the opportunity to investigate the efficacy of anti-infective treatments in HIV-infected patients during the perioperative period.

\section{Patients and methods}

\section{Definitions}

We defined the wound class at the surgical site of infection (SSI) using the definitions provided by the Centers for Disease Control and Prevention (CDC). An instance of surgical site infection was defined as an infection occurring within 30 days of the operative procedure, when

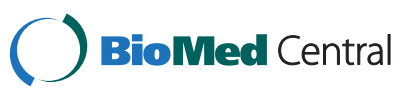


the patient had one or more of the following: (1) organisms isolated from an aseptically obtained culture of fluid or tissue from the surgical incision; (2) purulent drainage from the surgical incision; (3) at least one of the following: pain or tenderness, localized swelling, redness, or heat. SSIs were classified as being incisional, deep incisional or organ/space. Surgical procedures were classified as clean, contaminated or dirty. Sepsis was defined as the infection in association with systemic inflammatory response syndrome.

\section{Data collection}

Clinical data of HIV-infected patients undergoing surgery from January 2009 to December 2011 were retrieved using our computerized patient record system. Inclusion criteria: HIV-infected patients were identified and diagnosed by local Centers for the Disease Prevention and Control in different locations in China. All selected patients had records that contained thorough disease histories, including physical examinations, preoperative and postoperative routine examinations, and immune function tests.

\section{Patient group and study methods}

We stratified and compared the incidence of SSIs and sepsis according to both wound class and preoperative CD4 counts with breakpoint values of 200 and 350 cell/ $\mu \mathrm{L}$. Demographic and clinical information was entered into a database that included: type of surgical procedure, age, peripheral blood cell counts, plasma albumin, CD4 counts, and $\mathrm{CD} 4 / \mathrm{CD} 8$ ratios.

\section{Statistical analysis}

Date were analyzed using SPSS 16.0 statistical software (SPSS Inc., Chicago, IL). Results of all continuous data are presented here as mean \pm standard deviation. Continuous variables were compared by independent $t$-test. Univariate analysis of the categorical outcome was carried out using Chi-squared tests. $\mathrm{P}<0.05$ indicates statistical significance.

\section{Results}

Two hundred and sixty-six HIV-infected patients were included in this study. Their mean $( \pm \mathrm{SD})$ age was 42.3 $( \pm 13.1)$ years, and $237(89.1 \%)$ were male. There were six deaths in the study population, five of whom had organ/space SSI and developed sepsis. The SSI cumulative incidence rate was $46.6 \%$ (124 of 266). The incidence of incisional SSI was $37.6 \%$, deep incisional SSI was $5.3 \%$, and organ/space SSI was $3.8 \%$. Baseline characteristics of patients shown in (Table 1).

Univariate analysis revealed that the following variables were associated with the occurrence of sepsis:
Table 1 Baseline characteristics of patients

\begin{tabular}{lll}
\hline Variable & No. & $\begin{array}{l}\text { Percent of total } \\
\text { study population }\end{array}$ \\
\hline Age; median(IQR), yr & $42.3(10-74)$ & \\
\hline $\begin{array}{l}\text { Mortality(death } \\
\text { during hospitalization) }\end{array}$ & 6 & 2.3 \\
\hline Male sex & 237 & 89.1 \\
\hline Comorbidities & & \\
\hline Heart disease & 0 & 1.1 \\
\hline Diabetes & 3 & 17.7 \\
\hline Cancer & 47 &
\end{tabular}

preoperative WBC, hemoglobin, CD4, CD8 and CD4/ CD8 (Table 2).

At multivariate analysis, only preoperative $\mathrm{WBC}$, hemoglobin and $\mathrm{CD} 4$ remained significantly $(\mathrm{P}<0.05)$ associated with sepsis, (Table 3).

Comparisons of the incidence of sepsis according to preoperative CD4 counts shown in Table 4.

Patients with lower preoperative CD4 counts undergoing surgery were more likely to develop sepsis.Surgical procedures were classified as clean $(\mathrm{N}=82 ; 30.8 \%)$, contaminated $(\mathrm{N}=171 ; 64.3 \%)$ and dirty $(\mathrm{N}=13 ; 4.9 \%)$. The incidence of SSI differed significantly depending on wound class, and increased from $1.2 \%$ in patients with clean wounds to $100 \%$ in patients with dirty wound (Table 5).

Our data show that SSIs were frequent and differed widely by wound class. Patients with SSIs were more likely to develop postoperative sepsis than non-SSIs patients (Table 6).

\section{Discussion}

\section{Anti-infective treatment in the perioperative period}

HIV mainly invades and destroys CD4 T lymphocytes, causing CD4 counts to gradually decrease. In consequence of their significantly impaired immune function when the' $\mathrm{CD} 4$ count is below 350 cell/ $\mu \mathrm{L}$, HIV-infected patients are likely to get opportunistic infections and cancers and their mortality is then usually high [16]. At this stage ART is used, and usually includes two kinds of nucleosides and one kind of protease inhibitor. Patients using ART who undergo surgery need to continue ART use during the perioperative period [17]. Even if patients are undergoing gastrointestinal surgery and need to fast, they can take antiviral drugs. When a patient's' CD4 count is below 200 cell $/ \mu \mathrm{L}$, there is an additional high risk of acquiring fungal infections such as Pneumocystis carinii pneumonia which bring a marked increase in mortality $[18,19]$. Therefore SMZ and fluconazole are conventionally added to ART during the perioperative period to prevent $P$. carinii pneumonia and other fungal infections. If tuberculosis, cryptococcosis, 
Table 2 Comparisons of age and clinical date between sepsis group and non-sepsis group

\begin{tabular}{lllll}
\hline Parameters & Sepsis group & Non-sepsis group & $\mathbf{t}$ & $\mathbf{P}$ \\
\hline Age $(\mathrm{y})$ & $41.8 \pm 12.7$ & $42.7 \pm 13.8$ & -0.529 & 0.598 \\
\hline Viral load & $105027.01 \pm 2.58^{*} 10^{5}$ & $46203.79 \pm 1.02^{*} 10^{5}$ & 1.071 & 0.26 \\
\hline WBC $\left(\times 10^{9} / \mathrm{L}\right)^{*}$ & $6.15 \pm 3.317$ & $5.23 \pm 1.79$ & 2.625 & 0.010 \\
\hline Hemoglobin $(\mathrm{g} / \mathrm{L})^{*}$ & $113.7 \pm 24.9$ & $130.1 \pm 23.2$ & -5.349 & 0.000 \\
\hline Platelet $\left(\times 10^{9} / \mathrm{L}\right)$ & $213.4 \pm 114.5$ & $190.51 \pm 75.19$ & 1.821 & -5.349 \\
\hline CD4 (cell/ul)* & $172.6 \pm 163.4$ & $324.01 \pm 242.64$ & -2.132 & 0.070 \\
\hline CD8 (cell/ul)* & $666.9 \pm 485.4$ & $798.43 \pm 424.348$ & -3.836 & 0.034 \\
\hline CD4/CD8 & $0.30 \pm 0.25$ & $0.4532 \pm 0.3129$ & 0.000 \\
\hline
\end{tabular}

* Statistical significance.

candidiasis or similar infections have been found before surgery, anti-TB or antifungal treatments are clearly required to control the disease. In summary, HIV patients undergoing emergency surgery need prophylactic anti-infective drugs based on doctor/clinical experience, and effective anti-infective treatments are to be applied according to the results of resection of lesions and blood culture [20,21].

\section{Prophylactic antibiotics}

To reduce the incidence of surgical site infection, prophylactic antibiotics are generally used during the perioperative period. Because of the weakened immune function, HIV-infected patients are even more likely to need prophylactic antibiotics [22]. However, there are no reports specifically about how to use antibiotic in surgical patients who are HIV infected. We found that preoperative CD4 lymphocytes, WBC and hemoglobin are independent risk factors for sepsis. CD4 counts cannot be implied from white blood cell counts. Decline in CD4 $\mathrm{T}$ lymphocyte counts is often accompanied by decline in hemoglobin. Our principle in using prophylactic antibiotics was to use those antibiotics which can cover the most common infections according to surgical incision site and type of surgery. We took into account the likelihood of Gram-negative bacilli (enteric bacteria), grampositive cocci (Staphylococcus aureus) and anaerobic bacteria, and chose between two kinds of antibiotic combinations. We usually selected first-generation cephalosporins on clean wound surgery. For nine patients who

Table 3 Independent risk factors for perioperative sepsis estimated from multiple regression model

\begin{tabular}{llll}
\hline Risk factor & OR & $\mathbf{9 5 \% C l}$ & P value \\
\hline Preoperative CD4* & 6.069 & $1.001-1.010$ & 0.014 \\
\hline Preoperative CD8 & 0.469 & $0.998-1.001$ & 0.494 \\
\hline Preoperative CD4/CD8 & $0.2 \rightarrow 1$ & $0.027-8.425$ & 0.616 \\
\hline Preoperative Hemoglobin * & 4.302 & $1.001-1.036$ & 0.038 \\
\hline Preoperative Albumin & 0.12 & $0.962-1.028$ & 0.729 \\
\hline Preoperative WBC* & 5.814 & $0.719-0.996$ & 0.016 \\
\hline
\end{tabular}

were undergoing excision of thyroid tumor or breast tumor, we did not use any antibiotics and no SSI arose. In all, 82 patients underwent clean wound surgery and 81 had healing wounds. In future we may try not using any antibiotic for classIminor incisions. For giant splenectomy with cirrhosis and for internal fixation of femoral fractures, we still need prophylactic antibiotics, and they should be used longer than for normal surgery. We generally use antibiotics until wound have healed. The firstgeneration cephalosporins have a strong bactericidal activity for Gram-positive $S$. aureus, but for Gram-positive intestinal bacteria its bactericidal activity is less than second- and third-generation cephalosporins (ceftriaxone, etc.). Second-generation cephalosporins have advantages in the prevention of wound infection for class-IIincisions and gastrointestinal tract surgery, but its bactericidal activity is less than third-generation cephalosporins in the prevention of intra-abdominal infection. Prophylactic antibiotics should also cover common anaerobic bacteria for lower gastrointestinal surgery where there is significant pollution. Antibiotics such as piperacillin, cefoxitin, cefotetan, etc., can cover gram-negative enteric bacilli as well as anaerobic bacteria. Metronidazole and clindamycin should be included when other antibiotics do not have activity against anaerobic bacteria.

\section{Antibiotics for therapy}

Therapeutic drugs should be used for intra or postoperative infections. According to our statistical analysis of the clinical data, the lower the preoperative CD4 counts, the higher the incidence of sepsis. Our data also show that SSIs were frequent and differed widely by wound

Table 4 Incidence of postoperative sepsis according to preoperative cd4 counts

\begin{tabular}{lllll}
\hline Preoperative CD4 & Sepsis & Non-sepsis & $x^{2}$ & $\boldsymbol{p}$ \\
\hline$<200 \mathrm{cell} / \mu \mathrm{l}$ & $68(66.7 \%)$ & $34(33.3 \%)$ & 41.404 & $<0.01^{*}$ \\
\hline $200-349 \mathrm{cell} / \mu \mathrm{l}$ & $18(28.6 \%)$ & $45(71.4 \%)$ & & \\
\hline$\geq 350 \mathrm{cell} / \mu \mathrm{l}$ & $13(20.6 \%)$ & $50(79.4 \%)$ & & \\
\hline
\end{tabular}

* Statistical significance. 
Table 5 Incidence of SSIs according to wound class

\begin{tabular}{lllll}
\hline Wound class & Non-SSIs & SSIs & $\boldsymbol{x}^{2}$ & $\mathbf{p}$ \\
\hline clean & $81(98.8 \%)$ & $1(1.2 \%)$ & 104.349 & $<0.001^{*}$ \\
\hline contaminated & $61(35.7 \%)$ & $110(64.3 \%)$ & & \\
\hline dirty & 0 & $13(100 \%)$ & & \\
\hline
\end{tabular}

* Statistical significance.

class. The incidence of SSIs is high for Class II incisions because our study included many anal warts excision patients and these usually develop SSIs after surgery. Clearly, we should maintain clean wounds for superficial surgical site infections to reduce sepsis; our data show that the incidence of sepsis in the SSIs group was significantly higher than in the non-SSIs group. Therefore effective treatment should also be used for surgical site infection. Effective anti-infection treatment involves a multi-disciplinary knowledge for HIV-infected patients who may have tuberculosis, fungal infections and surgical site infections.

\section{Surgical risk and prognosis}

HIV-infected patients have a higher incidence of surgical complication and mortality than normal patients. Jeremiah L et al. [23] reported that the incidence of postoperative infectious complications was $55 \%$ and the 30-day mortality rate after surgery was $30 \%$ for HIVinfected patients. Our institution is a designated tertiary care university hospital for treatment of HIV-infected patients, so we have accumulated much perioperative anti-infection treatment experience. The mortality of HIV-infected patients undergoing abdominal surgery in our hospital was $7.7 \%$ which is significantly lower than previously reported data. Surgeons should pay attention to occupational exposure and aseptic technique in order to reduce SSIs and surgical trauma.

\section{Limitations of the study}

One of the limitations of the study was possible information biases due to the retrospective nature of the study design. Another was that the study did not control for possible confounders other than those investigated.

In conclusion, in order to reduce the incidence of infection complications and mortality, surgeons should combine multidisciplinary knowledge and carry out reasonable anti-infection treatments.

Table 6 Incidence of postoperative sepsis according to SSIs

\begin{tabular}{lllll}
\hline & Sepsis & Non-sepsis & $\boldsymbol{X}^{2}$ & $\boldsymbol{p}$ \\
\hline SSIs & $63(50.8 \%)$ & $61(49.2 \%)$ & 8.559 & $0.003^{*}$ \\
\hline Non-SSIs & $47(33.1 \%)$ & $95(66.9 \%)$ & & \\
\hline * Statistical significance & & &
\end{tabular}

\section{Ethical approval}

The study was approved by the Ethical Committee of Shanghai Public Health Clinical Center, Fudan University, Shanghai, China. (International index IORG0006364).

\section{Competing interests}

The authors have no financial or other conflicts of interest regarding this article.

\section{Authors' contributors}

$B L, L Z$ and $G Z$ conceived of the study, participated in its design and draft the manuscript. LL and JS participated in data collection. All authors read and approved the final manuscript.

\section{Acknowledgements}

Authors acknowledge Dr. W. Zhang, Dr. Y. Cao and Prof. Douglas in Shanghai Public Health Clinical Center affiliated to Fudan University for their critical comments and assistance to review and edit the manuscripts.

\section{Funding}

The study was supported by Research Foundation of Shanghai Public Health Clinical Center (RCJJP8).

\section{Author details}

1Department of Surgery, Shanghai Public Health Clinical Center Affiliated to Fudan University, 2901 Caolang Road, Shanghai, Jinshan District 201508, China. ${ }^{2}$ Department of Stomatology, Shanghai Public Health Clinical Center Affiliated to Fudan University, 2901 Caolang Road, Shanghai, Jinshan District 201508, China. ${ }^{3}$ Department of Emergency, The First Affiliated Hospital of Zhengzhou University, No.1 Jianshe Road, Zhengzhou 450052, China.

Received: 25 March 2012 Accepted: 8 August 2012

Published: 27 November 2012

\section{References}

1. Mangram A, Horan T, Pearson M, et al: Guideline for prevention of surgical site infection, 1999 [J]. Infect Control Hosp Epidemiol 1999, 20:250-278.

2. Evans RP: Surgical site infection prevention and control: an emerging paradigm. J Bone Joint Surg Am 2009, 91(Suppl 6):2-9.

3. Kirkland K, Briggs J, Trivette $S$, et al: The impact of surgical site infections in the 1990s: attributable mortality, excess length of hospitalization, and extra costs [J]. Infect Control Hosp Epidemiol 1999, 20:725-730.

4. McGarry S, Engemann J, Schmader K, et al: Surgical site infection due to Staphylococcus aureus among elderly patients: mortality, duration of hospitalization, and cost [J]. Infect Control Hosp Epidemiol 2004, 25:461-479.

5. Palmer S, Parker M, Hollingworth W: The cost and implications of reoperation after surgery for fracture of the hip [J]. J Bone Joint Surg $\mathrm{Br}$ 2000, 82:864-875.

6. Pollard T, Newman J, Barlow N, et al: Deep wound infection after proximal femoral fracture: consequences and costs [J]. J Hosp Infect 2006, 63:133-143

7. Edwards P, Lipp A, Holmes A: Preoperative skin antiseptics for preventing surgical wound infections after clean surgery. Cochrane Database Syst Rev 2004, (3):CD003949.

8. Ruiz-Perez I, Olry de Labry-Lima A A, López-Ruz MA, et al: Clinical status, adherence to HAART and quality of life in HIV-infected patients receiving antiretroviral treatment [J]. Enferm Infecc Microbiol Clin 2005, 23:581-590.

9. Mocroft A, Vella S, Benfield TL, et al: Changing patterns of mortality across Europe in patients infected with HIV-1. EuroSIDA Study Group [J]. Lancet 1998, 352:1725-1739.

10. Palella FJ, Delaney KM, Moorman AC, et al: Declining morbidity and mortality among patients with advanced human immunodeficiency virus infection. HIV Outpatient Study Investigators [J]. N Engl J Med 1998, 338:853-864.

11. Needham DM, Hogg RS, Yip B, et al: The impact of antiretroviral therapy on AIDS survival observed in a province-wide drug treatment program [J]. Int J STD AIDS 1998, 9:370-384. 
12. Teng $T$, Shao $Y$ : Scientific approaches to AIDS prevention and control in china [J]. Adv Dent Res 2011, 23:10-21.

13. Broder S: The development of antiretroviral therapy and its impact on the HIV-1/AIDS pandemic [J]. Antiviral Res 2010, 85:1-14.

14. Grulich AE, van Leeuwen MT, Falster MO, et al: Incidence of cancers in people with HIV/AIDS compared with immunosuppressed transplant recipients: A meta-analysis [J]. Lancet 2007, 370:59-72.

15. Slaven EM, Lopez F, Weintraub SL, et al: The AIDS patient with abdominal pain: A new challenge for the emergency physician [J]. Emerg Med Clin North Am 2003, 21:987-996.

16. LaRaja RD, Rothenberg RE, Odom JW, et al: The incidence of introabdominal surgery in acquired immunodeficiency syndrome: a statistical review of 904 patients. Surgery 1989, 105(2):175-179.

17. Foschi D, Cellerino P, Corsi F, et al: Impact of highly active antiretroviral therapy on outcome of cholecystectomy in patients with human immunodeficiency virus infection. Br J Surg 2006, 93(11):1383-1389.

18. Albaran RG, Webber J, Steffes CP: CD4 cell counts as a prognostic factor of major abdominal surgery in patients infected with the human immunodeficiency virus [J]. Arch Surg 1998, 133(6):626-631.

19. Emparan C, Iturburu IM, Ortiz J, Mendez JJ: Infective complications after abdominal surgery in patients infected with human immunodeficiency virus: role of CD4 + lymphocytes in prognosis [J]. Word J Surg. 1988, 22(8):778-782.

20. Delling RP, Leve MM, Carlet JM, et al: Surviving sepsis Campaign: International guidelines for management of severe sepsis and septic shock:2008[J]. Crit Care Med 2008, 36(1):296-327.

21. Samuel B: The development of antiretroviral therapy and its impact on the HIV-1/AIDS pandemic [J]. Antiviral Res 2010, 85:1-18.

22. Drapeau CM, Pan A, Bellacosa C, et al: Surgical site infections in HIVinfected patients: results from an Italian prospective multicenter observational study[]]. Infection 2009, 37(5):455-460.

23. Jeremiah $L$, Jessics $G$, Deneve, et al: CD4 count is predictive of outcome in HIV-positive patients undergoing abdominal operations[J]. Am J Surg 2010, 200(6):694-700.

doi:10.1186/1742-6405-9-36

Cite this article as: Liu et al.: Anti-infective treatment in HIV-infected patients during perioperative period. AIDS Research and Therapy 2012 9:36.

\section{Submit your next manuscript to BioMed Central and take full advantage of:}

- Convenient online submission

- Thorough peer review

- No space constraints or color figure charges

- Immediate publication on acceptance

- Inclusion in PubMed, CAS, Scopus and Google Scholar

- Research which is freely available for redistribution 